\section{A silent grunt for neonatal respiratory distress syndrome (or what's this EER ?)}

Sir,

Grunting in neonatal respiratory distress syndrome (RDS) appears to be a form of variable expiratory resistance. Simply inserting an endotracheal tube into an infant with acute RDS, and thus removing the grunt, may cause a marked deterioration in clinical condition. ${ }^{1}$ Moomjian et al. ${ }^{2}$ have completed the circle, replacing the grunt in their intubated babies, by an external expiratory resistance (EER). Perhaps extubation would have been simpler and equally satisfactory.

As well as questioning the rationale for the experiment, I would question some of the results. The authors state that the 'mean net work of breathing' was unaffected by EER. This is a fallacy, since the method usually used for calculating work of breathing does not take account of the shift in the pressure-volume loop, as lung volume is altered. When lung volume is increased by the application of EER, the increase is achieved by muscular effort on the part of the baby (and not, as in CPAP, by any external distending force). This extra effort, which may te considerable at high lung volumes, is not represented in the 'work of breathing' term. It is thus misleading to conclude that, because the 'work of breathing' was unaltered, the respiratory muscles were under no more stress. Indeed, the extra respiratory muscle load imposed by EER could merely hasten the onset of muscle fatigue in this susceptible group of infants. ${ }^{3}$

Clearly, without more appropriate measurements of lung mechanics, gas exchange, and respiratory muscle function, it would be premature to draw any conclusions concerning the clinical value of EER.

\section{References}

1 Harrison V C, Heese $\mathrm{H}$ de V, Klein M. The significance of grunting in hyaline membrane disease. Pediatrics 1968; 41 : 549-59.

2 Moomjian A S, Schwartz J G, Shutack J G, Rooklin A R, Shaffer T H, Fox W W. Use of external expiratory resistance in intubated neonates to increase lung volume. Arch Dis Child 1981; 56: 869-73.

3 Muller N, Gulston G, Cade D, et al. Diaphragmatic muscle fatigue in the newborn. J Appl Physiol 1979; 46: 688-95.

\section{Silverman \\ Department of Paediatrics and Neonatal Health, Hammersmith Hospital, Du Cane Road, London W12 OHS}

\section{Parenteral feeding and necrotising enterocolitis in very low birthweight infants}

Sir,

Eyal et al. ${ }^{1}$ believe that they have caused a reduction in the incidence of necrotising enterocolitis (NEC) in their hospital by the more extensive use of parenteral nutrition in very low birthweight infants. Unfortunately, the wellknown tendency for cases of NEC to occur in clusters makes the 'historical' controls they have used particularly unsuitable for this kind of study.

A similar change in management of very low birthweight infants occurred here in 1980 and 1981. During the first year parenteral nutrition was not often used, only if enteral nutrition was impossible. Six cases of NEC among 132 very low birthweight infants occurred; in the second year parenteral nutrition was used much more extensively and the infants were not fed enterally while ventilated, suffering from major recurrent apnoea, or tachypnoea exceeding 60 breaths a minute. Thirteen cases of NEC occurred among 181 very low birthweight infants none of which happened while the infant was receiving parenteral feeding, but symptoms appeared within a day or two of reaching full volume enteral feeds of fresh human milk or 'humanised' formula. Onset of the disease occurred between 1 and 8 weeks after birth; thus, although withholding enteral feeding protected against early NEC, the effect was to delay rather than prevent the disease. A small increase in incidence was seen but this could have been owing to the sporadic nature of the disease.

In most cases NEC is undoubtedly dependent on the presence of milk in the gut, but the need or desirability for total avoidance of enteral feeding in early weeks in very low birthweight infants is still far from proved. Provided that a low osmolality, well absorbed feed is used its exact nature may not be important; the total volume and rate of increase of volume of feed may be more relevant. Concern that poor weight gain may have later consequences in terms of brain development prompts many neonatal units to overload the capacity of the gastrointestinal system of these tiny infants. A combination of enteral and parenteral feeding may allow the optimal solution by allowing a very slow increase in enteral load during the first 2 or 3 weeks with adequate calorie intake. In a large hospital the use of such a conservative feeding regimen has already been shown to reduce the incidence of NEC to insignificant levels without the problems of wholesale parenteral feeding. ${ }^{2}$

\section{References}

1 Eyal F, Sagi E, Arad I, Avital A. Necrotising enterocolitis in the very low birthweight infant: expressed breast milk feeding compared with parenteral feeding. Arch Dis Child 1982; 57: 274-6.

2 Brown E G, Sweet A Y. Preventing necrotizing enterocolitis in neonates. JAMA 1978; 240: 2452-4.

RICHARD COOKE Department of Child Health, Regional Neonatal Intensive Care Unit, Liverpool Maternity Hospital, Oxford Street, Liverpool L7 7BN

Dr Eyal and co-workers comment:

The suggestion that the sharp reduction in the incidence of NEC in our very low birthweight infants after the 